\title{
Postdisaster Reconstruction of Horizontal Infrastructure Systems: A Review of the Christchurch Rebuild
}

\author{
K. A. MacAskill \\ Department of Engineering, University of Cambridge
}

\begin{abstract}
This paper investigates the decision-making processes guiding postdisaster infrastructure reconstructionconcentrating on wastewater, water supply, stormwater and road networks ("horizontal infrastructure"). It draws on empirical analysis of the postearthquake reconstruction currently underway in Christchurch, New Zealand.
\end{abstract}

Restoring infrastructure services to provide at least a basic level of essential services after a disaster helps wider economic recovery. Subsequently, there is pressure to restore infrastructure services to predisaster levels as quickly as possible. Reconstruction programmes thus commence in highly uncertain decision-making environments and are reactive to perceived, immediate needs. The extent and nature of the work is later clarified and re-evaluated as projects progress. This context of postdisaster response presents unique challenges in terms of design and delivery processes.

The focus of this paper is to address the impact of such institutional and organizational arrangements on postdisaster reconstruction decisions. It also discusses changes in decision making that occur over time as needs change. It does this through examining changes in the overall design philosophy and approaches to prioritization and deferment in the Christchurch case study.

\section{INTRODUCTION}

Over the past few decades, research into postdisaster reconstruction has endeavoured to develop an understanding of the fundamental elements of best-practice approaches for disaster recovery. This has contributed to emerging theories on housing reconstruction (Hayles, 2010); postdisaster planning processes (Olshansky, Hopkins, \& Johnson, 2012); and discussion of institutional, regulatory, and financing arrangements (Fengler, Ihsan, \&Kaiser, 2008; Rotimi, 2010). There has also been a recent focus on the role of donor organizations in decision making, particularly international organizations that intervene in managing a postdisaster situation (Kennedy, Ashmore, Babister, \& Kelman, 2008). Understanding the reconstruction process from the perspective of restoring a city's wastewater, water supply, stormwater and transport services (collectively defined here as "horizontal networks") is an important yet overlooked aspect of postdisaster reconstruction. These networks are fundamental to urban development. Governments around the world are concerned with the degradation of network assets and insufficient investment in infrastructure (e.g., Engineers Australia, 2010; American Society of Civil Engineers [ASCE], 2013). Postdisaster reconstruction typically involves significant capital investment into these networks. While the capital available may be limited in terms of repairing damage caused by a disaster, the budget can be many times greater than the typical annual renewal and maintenance budget. Decisions on how to distribute this money have long-term implications for both the cost of maintaining the infrastructure and the ability for communities to function and grow. Understanding the process behind these decisions will contribute to a better understanding of the challenges for introducing improvements and acting upon perceived opportunities for change. The process is influenced by both the structure of funding arrangements and the boundaries placed on the process by which various options are assessed. These boundaries are influenced by the size and complexity of recovery efforts, where the damage caused overwhelms the capacity of existing local government and new organizational relationships form to support the recovery.

This paper reviews how infrastructure decisions are influenced by the institutional (i.e., the policies, systems, and processes) and organizational arrangements associated with postdisaster reconstruction in Christchurch, New Zealand, following a series of earthquakes that occurred in 2010 and 2011. It presents an initial analysis associated within an ongoing research project on decision-making processes directing infrastructure reconstruction. This analysis is informed by existing postdisaster reconstruction literature, government and project information directly related to Christchurch reconstruction, and an initial phase of semistructured interviews with professionals 
(primarily engineers) involved in the reconstruction process in Christchurch. This work was also informed by the author's previous experience working as an engineer in the reconstruction.

The analysis is presented in two parts. It starts with an overview of the Christchurch reconstruction and sets the context for the reconstruction of horizontal infrastructure. This discussion includes a brief introduction to organizational roles in the reconstruction. The analysis then moves onto examining the impact of institutional and organizational arrangements on decisions. It explores how the design philosophy changed over time and how reconstruction effort is scoped at a project level. It is important to highlight that this paper does not analyse the appropriateness of the organizational boundaries, scoping, and prioritization, which will be considered in future work. Rather, the aim of this paper is to provide organizational context and explore the influence this has on the decision-making process.

\section{CHRISTCHURCH CONTEXT}

\subsection{Overview}

Christchurch, with a population of approximately 370,000 , is the main urban centre in the Canterbury region of New Zealand. The region was hit by a series of earthquakes during 2010 and 2011. The first earthquake occurred in September 2010. Thousands of aftershocks have followed, including three major events that occurred in February 2011, June 2011, and December 2011. Homes were damaged, Christchurch's Central Business District was severely affected, and horizontal infrastructure systems across the city sustained various levels of service loss. The February event caused the worst damage.

The Christchurch City Council (CCC) set up the Infrastructure Rebuild Management Office (IRMO) to oversee the reconstruction process following the initial September event. This was formally launched in February 2011, just prior to the second major earthquake (CCC, 2011). The IRMO arrangement involved four lead contractors partnered with design. Contracts were won through a bidding process, and each contractor was allocated an area in the city to reinstate services.

The increased level of damage caused by the February 2011 earthquake triggered a change in approach to the reconstruction process. It prompted the national government to set up the Canterbury Earthquake Recovery Authority (CERA) via the Canterbury Earthquake Recovery Act 2011, introducing national-level governance. Alongside this process, the CCC recognized that the IRMO arrangement was not suitable for the larger scale of repair required (Office of the Auditor General (OAG), 2013). Ultimately, the Stronger Christchurch
Infrastructure Rebuild Team (SCIRT) was formed as the joint venture organization to implement the reconstruction through an Alliance agreement. ${ }^{1}$ SCIRT is responsible for reconstructing the horizontal infrastructure within Christchurch city, reporting to the New Zealand Transport Authority (NZTA), CCC, and CERA. Estimates as of 2012 suggest that $528 \mathrm{~km}$ of sewer pipes, $124 \mathrm{~km}$ of water mains, and $1,021 \mathrm{~km}$ of roads were damaged (OAG, 2012). The estimate for delivering SCIRT's work is NZ $\$ 2.496$ billion, which is jointly funded by the New Zealand national government (through CERA and NZTA) and the CCC (OAG, 2013).

\subsection{Reconstruction of Horizontal Networks: The Strategy}

The Christchurch case presents a useful demonstration of how the scale of an event affects the nature of the response. Damage caused in September 2010 was significant, but CCC retained authority to manage the reconstruction process. IRMO operated on a project-by-project basis where contractors and consultants typically responded to specific issues as they were identified.

The transition to SCIRT was accompanied by a transition to a catchment-level approach where design teams within SCIRT were allocated project areas based on wastewater network catchments (Figure 1). This placed greater emphasis on adopting a more strategic consideration of options for reconstruction and seeking ways to incorporate resilience to future earthquakes. For example, structural damage in a specific location could be placed in the context of the operation of the catchment network. Assessment of the wastewater networks included considering alternative technologies and adjusting the network layout to replace damaged sections of the existing low-gradient, gravity-fed system. Stormwater network analysis included assessing the increased risk of flooding and the overall capacity of the network, which required understanding catchment flows. Water supply and road assessment proceeded primarily on a street-by-street basis; however, some adjustments were made for closure of streets in red-zoned land (red-zoned land is discussed further in Section 3.2.).

\section{INSTITUTIONAL AND ORGANIZATIONAL ARRANGEMENTS: IMPACT ON DECISIONS}

\subsection{Design Philosophy and Specifications}

The Alliance agreement sets specific boundaries around SCIRT's scope of work. The agreement was predicated on restoring services to Christchurch, with the primary objective "To return the infrastructure networks to a condition that meets the levels of service prior to the 4 September 2010

\footnotetext{
${ }^{1}$ Please refer to the OAG report for further detail around the Alliance agreement.
} 


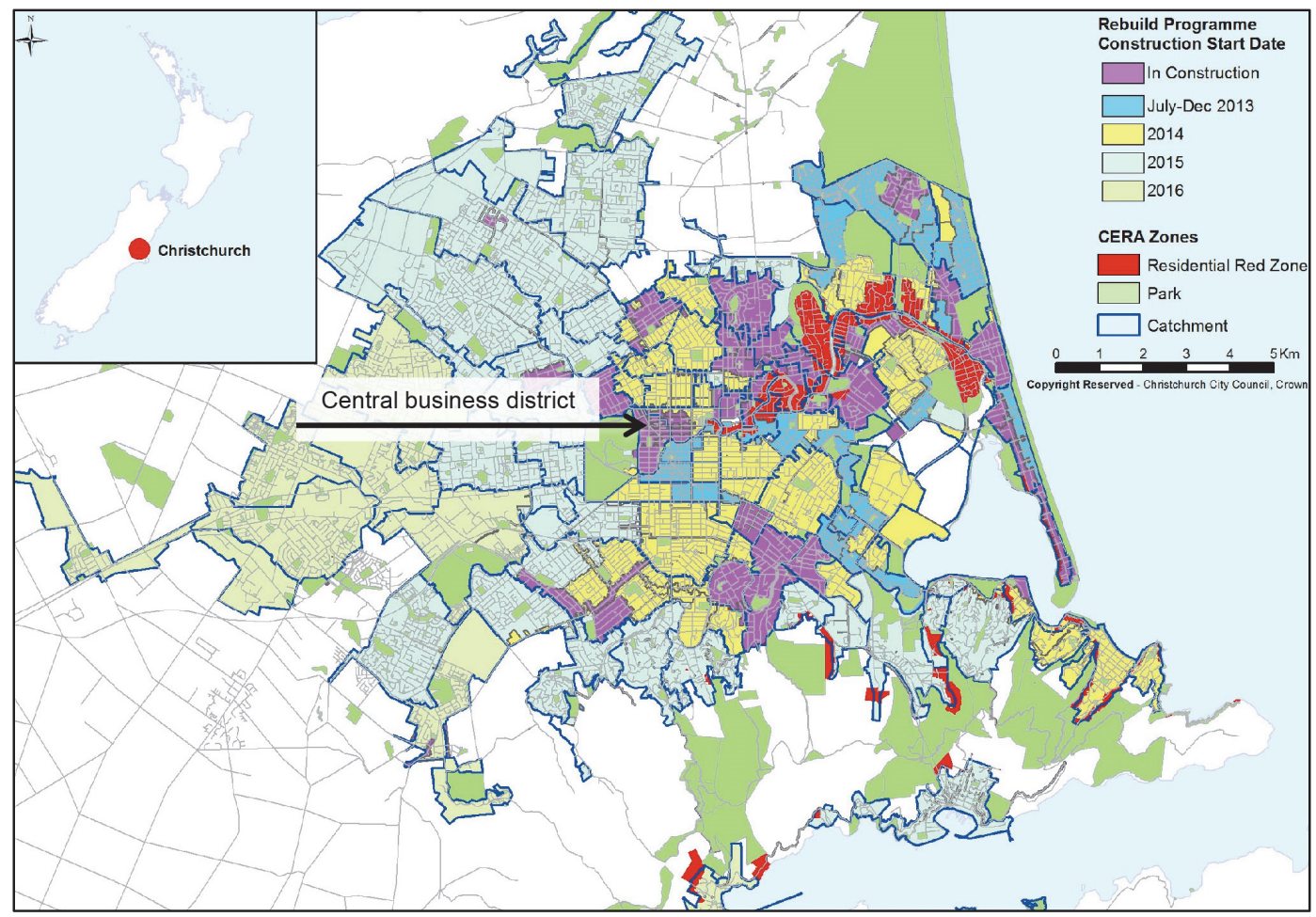

Figure 1. Reconstruction catchment areas, coloured according to rebuild programme start date. Map sourced from SCIRT data (map dated July 2013). Prioritization of areas forreconstruction was determined through consideration of multiple factors such as operational priorities, interdependencies, key services, external factors and other constraints (e.g. resources [SCIRT, n.d. a])

earthquake within the timing constraints of the rebuild" (CCC, NZTA, \& CERA, 2013, p.3). In essence, this meant replacing damaged infrastructure on a like-for-like basis, where designers apply modern equivalent standards and materials. A secondary objective established that: "Where restoration work is undertaken, and where reasonably possible and economically efficient and viable, greater resilience is to be incorporated into the network" (CCC, NZTA \& CERA, 2013, p.3). The definition of resilience is a topical debate in academic literature (as discussed in Alexander, 2013). From SCIRT's perspective (and for the purposes of this discussion), resilience is "the ability for the infrastructure (the roads, pipes etc.) to resist future earthquake damage. Improved infrastructure resilience can be achieved by using better materials, adopting higher construction standards, creating new systems, or minimising hazards." (SCIRT, n.d. b) ${ }^{2}$ It proved difficult in some circumstances to justify improved resilience due to, for example, extra costs where the extent of a design needs to go beyond a specific damaged area to meet tie-in requirements, or the costs of augmenting substandard systems. Opportunities to make step-change improvements to the service or capacity of the network are considered but require approval for extra funding. To date, a

\footnotetext{
${ }^{2}$ Other definitions of resilience vary depending on the context. Even in the context of resilience to natural hazards, the discussion "ranges from ecological to social systems and also covers some socio-ecological spaces in-between" (Kuhlicke, 2010, p. 61).
}

greater proportion of this funding has been allocated to improving the wastewater network compared to the storm water network and roads, with some allocation towards improving bridges.

\subsection{Assessment and Design Process}

An important aspect of any recovery process is the ability to change over time in light of new information (Olshanksy, Johnson, \& Topping, 2006). SCIRT's strategy initially focused on suburbs with the most badly damaged wastewater infrastructure, prioritizing the need to restore this service. ${ }^{3}$ The prioritization was determined on the basis of a multicriteria assessment. Infrastructure Recovery Technical Standards and Guidelines (IRTS\&G) were developed by SCIRT's clients to provide a consistent basis on which to justify restoration decisions. This document provided a basic framework that, in its early versions, supported a strategy of intervention at a threshold level of damage. While the reconstruction was always fundamentally guided by a principle of restoring services, the earlier versions of the IRTS\&G had provided a prescriptive approach focused on fixing structural damage. This was generally viewed to be appropriate guidance for the most damaged wastewater networks. Here, the approach was essentially based on both the extent

\footnotetext{
${ }^{3}$ Excluding the Central Business District, where demolition works had to take place before horizontal infrastructure damage could be adequately assessed and repaired or rebuilt.
} 
of pipe fracturing and the loss of longitudinal grade, which can affect the ability of gravity-fed systems to operate.

As design teams progressively moved into assessing low to moderately damaged wastewater catchments, it became clear that adherence to the threshold damage specifications outlined in the IRTS\&G did not provide entirely suitable guidance for these areas. This approach was not structured in a way that encouraged the utilization of the remaining operational life of moderately damaged assets. As the focus shifted towards these areas, the basis of decisions was modified to place more emphasis on returning a minimum level of network services to the city. This approach was predicated on the basis that there is a finite level of available funding where the confirmed budget was less than early target estimates (this is discussed in the OAG report published in 2013). This funding needed to be allocated in a way that restored pre-earthquake levels of service from a citywide perspective; a process requiring trade-offs as to where to invest. In less damaged areas, there was an option to reduce reconstruction investment and accept higher levels of maintenance where the existing infrastructure can provide a minimum level of service. The increased maintenance cost is offset by reduced maintenance requirements of new infrastructure introduced in other areas.

There had nevertheless always been a mechanism in the design process at SCIRT to challenge the guidance of the IRTS\&G on any particular project. This process involved a Scope and Standards (S\&S) committee that reviewed applications from design teams requesting deviation from the standards specified in the IRTS\&G. ${ }^{4}$ The shift away from prescriptive intervention provided greater scope for engineers to consider alternative options. The IRTS\&G was subsequently amended to provide better guidance for considering levels of service.

One wastewater project in particular went through several design reviews, where design engineers looked for opportunities to pursue better value solutions because damaged assets still had significant remaining operational life. An important aspect here was that most of the original design of the existing wastewater network (primarily constructed in the 1960s) did not meet the minimum grade specification of current local standards. SCIRT's project engineers believed that strict adherence to the intervention-based design guidelines in this case would overprescribe

\footnotetext{
4 All projects required sign-off by technical council staff representing CCC as asset owner representatives within SCIRT. The S\&S committee is chaired by the CCC, and consists of six CCC members, one NZTA representative and one CERA representative.
}

requirements for repair. A lifecycle cost analysis suggested that the up-front cost of relaying all subgrade pipes to more resilient standards (through steeper grades) was not warranted. The analysis included the possibility of earthquake damage occurring. The engineers proposed to relay pipes that had sustained a series of failures to "bestavailable grade," rather than to full compliance of the current standards. This proposal to deviate from guidelines was initially rejected by the $S \& S$ committee. However, as intervention-based guidelines were gradually superseded by target costs for meeting minimum levels of service, this proposal was reviewed and some deviations were ultimately accepted.

It was estimated that the total cost of a fully compliant option for this project (in terms of strictly following intervention-based guidelines) was \$NZ 44 million. The current estimate is NZ \$10.9 million. The current design introduces less resilience into this catchment area compared to the original proposal. There is also an element of deferral where pipes not replaced now will have a shorter asset life than new pipes and may require earlier replacement. However, reduced construction costs outweighed the risk of future damage and subsequent need for repair. In isolation, this project may be viewed as a lost opportunity to increase infrastructure resilience through the use of new materials and through designing a system with steeper grades. However, the accepted design makes greater use of the remaining asset life in the existing network. The savings made here also allowed for reallocation of the remaining budget for SCIRT into other areas of the city's infrastructure. This is an important factor where there is limited funding available to reconstruct the city's assets.

\subsection{Determining Intervention}

The assessment process for each network will not be addressed in this paper. While based on the same general philosophy, the reconstruction approach to each network has particular nuances. Aspects of the storm water network restoration are discussed below to demonstrate some of the challenges involved.

The storm water network in Christchurch is defined through two key components:

- The primary network, which consists of underground pipes, sumps, outlet structures, and stop banks.

- The secondary network, which is the road infrastructure-kerbs and channels to direct surface water flow.

SCIRT is "primarily concerned with the "hardengineered' assets" (CCC, NZTA \& CERA, 2013). It 
is within the assessment remit to evaluate increases in flooding risk. However, in essence, any upgrade in the system in terms of adding capacity beyond what existed prior to the earthquake requires sourcing funding beyond that approved for SCIRT work. Also, area-wide land settlement and reduced capacity of waterways impacted the capacity of the storm water network, but these issues are not directly associated with damage sustained by the "hard-engineered" assets.

In practice, it was challenging for storm water engineers to apply the principle of like-for-like replacement. Direct replacement of the damaged pipe network will not necessarily result in restoration of prior network capacity because changes in land levels have resulted in loss of hydraulic grade in some areas. This essentially meant that there is a reduction in the capacity of the system, as demonstrated in Figure 2. Where augmenting the primary system was considered as a practical intervention for restoring network capacity, engineers, asset owners, and funders had varying views on what level of repair was justified through the intervention-level guidance, what constitutes added resilience, and whether or not there was a need to source extra funding beyond that approved for SCIRT.

A significant amount of land in the eastern suburbs is at risk of flooding. This was outlined in a recent report on climate change risk for the CCC by Tonkin and Taylor (2013) and was substantiated in a 48hour storm event in March 2014. Flooding was a prior risk that has been exacerbated by land movement associated with the earthquakes.

In one SCIRT storm water project, a new storm water retention basin was proposed to restore a minimum level of drainage capacity to an area where no basin had previously existed. Reduction in land height in the area significantly reduced the hydraulic capacity of the primary network that existed prior to the earthquakes. The network relied on a storm water outfall in a tidal environment. The system is now more vulnerable to impact from high tide levels due to land settlement, and the capacity for storm water discharge is reduced (similar to the situation outlined in Figure 2). This was a case where a significant increase in risk of flooding attributable to earthquake damage justified augmenting the existing system with a storm water basin. There was also, fortuitously, reserve land in the area that could be made available for this purpose.

In other areas, it was difficult to justify intervention to restore existing networks according to modern capacity standards. Issues associated with lack of capacity were as much associated with historical shortcomings of the network as they were a

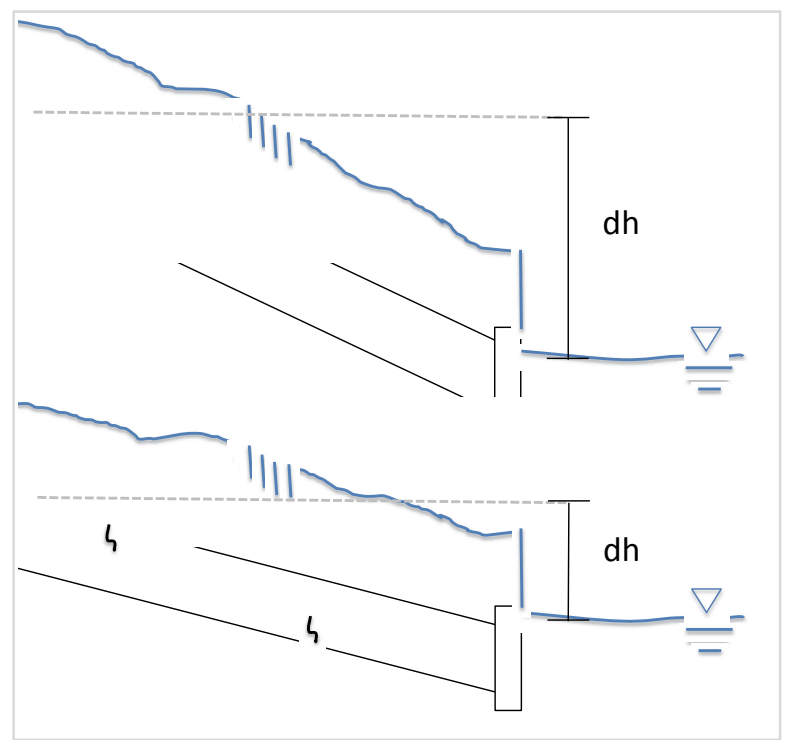

Figure 2. Conceptual sketch of longitudinal pipe and section with a tide-affected outflow. The top section shows the pre-earthquake situation. The change in hydraulic head (indicated by "dh") is reduced in the lower section as a result of land movement caused by earthquakes. This reduces the capacity of the storm water system to drain in low-lying land, particularly during high tides.

consequence of earthquake damage. The cost to improve the system could not be justified under SCIRT funding.

An additional complicating factor for designing effective infrastructure solutions is the uncertainty around the future use of red-zoned land in the city. Land was zoned red in areas that sustained high levels of damage, had a high risk of future earthquake or flood damage, and where it is considered uneconomical to repair properties (OAG, 2012). Much of this land area borders the Avon River. (refer back to Figure 1 to see the relative extent of red zone areas). In some places, this land was in areas that are potentially suitable for locating storm water retention basins. While SCIRT could make recommendations to CERA, it has no authority to influence decisions regarding red-zoned land. Now, over three years since the February 2011 earthquake, there is still no clear picture about the future of the red zone, which is both a highly political and a complex insurance issue. The reconstruction of horizontal infrastructure has moved ahead in the absence of clarity here. As a general rule, building any infrastructure in red-zoned land has been avoided to date unless it has involved maintaining existing connections to service green-zoned land.

\section{DISCUSSION}

This paper examined the decision-making processes guiding postdisaster reconstruction of horizontal infrastructure. It has highlighted unique challenges that the postdisaster context poses for design and delivery processes. The Christchurch case study demonstrates the importance of maintaining a flexible 
approach during the course of the recovery period. The response associated with earlier phases of the recovery was adjusted as needs changed over time. A twofold change in philosophy throughout the recovery effort provided greater allowance for using engineering judgment and applying more strategic thinking. This was demonstrated here primarily in the context of reconstructing the wastewater network which was significantly impacted by the changes. This first change is attributed to the move from IRMO location-based repairs to SCIRT catchment performance assessment. The second change was in the adjustment of repair philosophy away from prescriptive guidelines to attaining a minimum citywide level of service. This gave more emphasis on understanding the remaining asset life and maintenance costs of infrastructure assets in an effort to achieve a more effective distribution of available funding.

This paper also outlined the challenges associated with restoring infrastructure services to predisaster levels and in attempting to capitalise on opportunities to improve the network. A key part of the challenge is in determining the actual loss of network capacity attributable to the earthquakes. Costs of augmenting existing networks had to be justified on a like-for-like basis, which is often not a clear-cut evaluation. While there is ostensibly an opportunity to introduce improvements as part of the reconstruction process, capacity upgrades will generally entail extra costs, and this cannot always be accommodated within the available funds. Finally, uncertainty over future land use limits holistic decision making for the horizontal infrastructure reconstruction task.

\section{CONCLUSION}

The question that underlies a significant amount of existing research into postdisaster reconstruction is essentially: what is the best way to facilitate the reconstruction process? The Christchurch case provides some insight into how decisions related to reconstructing horizontal infrastructure are made. Firstly, while taking the opportunity to improve networks and increase resilience are commendable ambitions, a lot of work and time was required to create a common understanding amongst the funders (CCC, NZTA, and CERA) and implementers (SCIRT) as to what this actually means in reality. Secondly, an understanding of requirements developed through time as those managing the reconstruction developed a more tangible sense of the nature of damage, possible repair options, cost of work, and available funding. Thirdly, SCIRT was able to react to changing conditions throughout the reconstruction process. However, it did so within the bounds of the Alliance agreement. Delivering on this agreement meant making decisions without certainty on related reconstruction issues outside of SCIRT's remit.

\section{ACKNOWLEDGMENTS}

The author gratefully acknowledges the input from SCIRT staff. Thanks to Regan Smith, Jeanette White, Russell Davies, and Lucy Conrad for projectspecific details; Abigail Walshe for providing Figure 1 ; and to the SCIRT management team for supporting this research.

\section{REFERENCES}

Alexander, D. E. (2013). Resilience and disaster risk reduction: An etymological journey. Natural Hazards and Earth System Sciences Discussions, 1(2), 1257-1284. http://dx.doi.org/10.5194/nhessd1-1257-2013

American Society of Civil Engineers. (2013, March). Report card for America's infrastructure [PDF]. Reston, VA: American Society of Civil Engineers. Retrieved from http://www.infrastructurereportcard. org/a/documents/2013-Report-Card.pdf

Christchurch City Council. (2011, February 11).

Rebuild of underground services underway throughout Christchurch. Retrieved from http://www.ccc.govt.nz/thecouncil/newsmedia/ mediareleases/2011/201102112.aspx

Christchurch City Council, New Zealand Transport Agency, \& Canterbury Earthquake Recovery Authority. (2013). Infrastructure recovery technical standards and guidelines. Christchurch, New Zealand.

Engineers Australia. (2010). Australian infrastructure report card. Retrieved from www.engineers australia.org.au/irc

Fengler, W., Ihsan, A., \& Kaiser, K. (2008). Managing post-disaster reconstruction finance: International experience in public financial management (Policy Research Working Paper 4475). Chicago, IL: World Book. http://dx.doi.org/10.1596/1813-9450-4475

Hayles, C. S. (2010). An examination of decision making in post disaster housing reconstruction. International Journal of Disaster Resilience in the Built Environment, 1(1), 103-122. http://dx.doi.org/ 10.1108/17595901011026508

Kennedy, J., Ashmore, J., Babister, E., \& Kelman, I. (2008). The meaning of "build back better": Evidence from post-tsunami Aceh and Sri Lanka. Journal of Contingencies and Crisis Management, 16(1), 24-36. http://dx.doi.org/10.1111/j.14685973.2008.00529.x

Kuhlicke, C. (2010). Resilience: A capacity and a myth: Findings from an in-depth case study in disaster management research. Natural Hazards, 67(1), 61-76. http://dx.doi.org/10.1007/s11069010-9646-y

Office of the Auditor-General. (2012). Roles, responsibilities, and funding of public entities after 
the Canterbury earthquakes. Retrieved from http://www.oag.govt.nz/2012/canterbury

Office of the Auditor-General. (2013). Effectiveness and efficiency of arrangements to repair pipes and roads in Christchurch. Retrieved from http://www.oag.govt.nz/2013/scirt

Olshansky, R. B., Hopkins, L. D., \& Johnson, L. A. (2012). Disaster and recovery: Processes compressed in time. Natural Hazards Review, 13(3), 173-178. http://dx.doi.org/10.1061/ (ASCE)NH.1527-6996.0000077

Olshansky, R. B., Johnson, L. A., \& Topping, K. C. (2006). Rebuilding communities following disaster: lessons from Kobe and Los Angeles. Built Environment, 32(4), 354-374. http://dx.doi.org/ 10.2148/benv.32.4.354

Rotimi, J. O. B. (2010). An examination of improvements required to legislative provisions for post disaster reconstruction in New Zealand (Doctoral dissertation). Retrieved from University of Canterbury Research Repository. Retrieved from http://hdl.handle.net/10092/4145

Stronger Christchurch Infrastructure Rebuild Team. (n.d. a). How we plan our work. Retrieved from http://strongerchristchurch.govt.nz/about/methods\# priorities

Stronger Christchurch Infrastructure Rebuild Team. (n.d. b). Are you taking this opportunity to improve the infrastructure? Retrieved from http://stronger christchurch.govt.nz/resources/faq/are-you-takingthis-opportunity-to-improve-the-infrastructure

Tonkin \& Taylor. (2013). Effects of sea level rise for Christchurch City. Christchurch, New Zealand: Christchurch City Council. 